\title{
BMJ Open Multiple barriers to participation for people with psychosocial disability in Dehradun district, North India: a cross- sectional study
}

\author{
Kaaren Mathias, ${ }^{1}$ Hira Pant, ${ }^{2}$ Manju Marella, ${ }^{3}$ Lawrence Singh, ${ }^{4}$ GVS Murthy, ${ }^{2}$ \\ Nathan Grills ${ }^{3}$
}

To cite: Mathias K, Pant $\mathrm{H}$, Marella M, et al. Multiple barriers to participation for people with psychosocial disability in Dehradun district, North India: a crosssectional study. BMJ Open 2018;8:e019443. doi:10.1136/ bmjopen-2017-019443

- Prepublication history for this paper is available online. To view these files, please visit the journal online (http://dx.doi. org/10.1136/bmjopen-2017019443).

Received 4 September 2017 Revised 24 December 2017 Accepted 15 January 2018

Check for updates

${ }^{1}$ Landour Community Hospital, Mussoorie, Uttarakhand, India ${ }^{2}$ Public Health Foundation of India, Indian Institute of Public Health, Hyderabad, Telangana, India

${ }^{3}$ Nossal Institute for Global Health, University of Melbourne, Melbourne, Victoria, Australia

${ }^{4}$ AKS Hope, Dehradun, Uttarakhand, India

Correspondence to Dr Kaaren Mathias; kaaren@eha-health.org

\section{ABSTRACT}

Objectives This study used a population-based cross-sectional survey to describe the prevalence of psychosocial disability and unmet need for access to services in North India.

Setting This study was conducted in Dehradun district, Uttarakhand, in 2014.

Participants A population-based sample of 2441 people over the age of 18 years.

Primary outcome measures The Rapid Assessment of Disability survey tool identified people with disability and used an adapted version of the Kessler scale to identify those with psychosocial disability. It additionally collected information on socioeconomic variables, access to community services and barriers to participation. Prevalence of psychosocial disability and unmet needs and descriptions of barriers to services were calculated, and multivariable logistic regression was used to assess associations between risk factors and psychosocial disability.

Results Prevalence of psychosocial disability was $4.8 \%$ and $75 \%$ of participants with psychological distress also reported comorbid functional impairments. Adjusted ORs for depression of more than two were found for people who were unschooled, unemployed and of moderate or poor socioeconomic status. The unmet need for access to services was significantly higher in every domain for people with psychosocial disability and was more than $25 \%$ in the areas of employment, health service access and community consultation. People with psychosocial disability encountered greater barriers in each domain compared with controls.

Conclusions People who are poor, uneducated and unemployed are two to four times more likely to have psychosocial disability in Dehradun district. They face unmet needs in accessing community services and perceive negative social attitudes, lack of physical accessibility and lack of information as barriers limiting their participation. Social policy must increase access to education and reduce poverty but additionally ensure action is taken in all community services to increase information, physical accessibility and social inclusion of people with psychosocial and other forms of disability.
Strengths and limitations of this study

- This study uses a community-based randomly selected sample of adults to assess prevalence of psychosocial disability and barriers to participation.

- This study presents one of the first assessments of barriers to community participation for people with psychosocial disability in India.

- A limitation of this study is that it uses an adapted Kessler 6 scale as a screening tool to assess psychosocial disability rather than a definitive clinical assessment.

- The cross-sectional design cannot indicate causation.

\section{INTRODUCTION}

Mental illness was the leading cause of years lived with disability in the 2010 Global Burden of Disease study, with the majority of people affected living in low and middle-income countries (LMIC). Psychosocial disability as a term refers to people who have either received a mental health diagnosis or who have identified that they experience limitations in functioning in basic psychological and social activities, and who have experienced the negative social impacts of psychological or social disability including discrimination and exclusion. ${ }^{1}$ We use this term to support our stance of a social model of disability that recognises that many barriers experienced are related to the way society limits the personal, social, political and economic power of people with disability, ${ }^{12}$ can be constant or episodic and can be understood assessing activities of daily living and functional ranges ${ }^{3}$

To allow people with disabilities to fully enjoy all human, political and civil rights and fundamental freedoms, the United Nations Convention on the Rights of Persons with Disability (UNCRPD) acknowledges 'the importance of accessibility to the physical, 
social, economic and cultural environment, to health and education and to information and communication'. ${ }^{4}$ Yet in India, and beyond, at national and state levels, this accessibility is significantly limited for many people with disabilities due to lack of implementation and regulation of law and policies. Further barriers include stigma, lack of financial resources and a lack of evidence-based research to quantify and implement solutions.

While people with psychosocial disability (PPSD) are often physically able to access services, barriers for utilisation include real and perceived stigma, limited motivation and self-belief and limited social role functioning. Stigma and discrimination is a prevalent experience for person with psychosocial disability (PPSD) in all parts of the world, and limits access to healthcare, opportunity and capacity for community participation ${ }^{5}$ It results in unequal access to resources, capabilities and rights which leads to health inequalities and social exclusion. ${ }^{6}$ Policy guidance on social inclusion and community participation in the sphere of global mental health has been broad, with few specifics on what to measure and how to operationalise or measure participation by affected individuals. ${ }^{7}$ In a paper describing the top 40 challenges for global mental health in 2011, to develop culturally informed methods to eliminate the stigma, discrimination and social exclusion of patients and families across cultural settings' was ranked as the second most important challenge. ${ }^{8}$ To engage and respond to the real challenges for social exclusion and psychosocial disability, we recognise the contribution of the larger social, economic, cultural and political environment to the prevalence and experience of psychosocial disability. It is clear that people with greater social and economic disadvantage are at greater risk of common mental illnesses ${ }^{9}$ and that this is particularly evident in LMIC. ${ }^{10}$

The importance of social inclusion for access to services has become more evident, and it has been identified as key to reducing health inequalities by increasing health-related knowledge, ${ }^{11}$ improving people's control of their health and promoting healthy behaviours. ${ }^{12}$ Participation can impact directly and indirectly on health. Opportunity to participate in accessing sanitation, clean water, health and education services can directly improve health. However, participation in domains of life such as community consultations, religious gatherings and disabled persons groups can also indirectly impact health through strengthened social capital, social inclusion and a sense of belonging. ${ }^{11} 13$

There is limited research in LMIC, and particularly little evidence from setting of North India, to understand the ways that social exclusion and disability interact for PPSD in access to services and community participation. ${ }^{7814}$ Within a broader study of diability, ${ }^{15}$ the aim of this study was to describe the prevalence of psychosocial disability and its association with social determinants of health and to examine barriers to participation among people with and without psychosocial disability.
METHODS

\section{Setting}

Publicly funded human resources and infrastructure for disability in Dehradun district, Uttarakhand, are limited, and although the state provides some residential institutional care for people with intellectual disability, and runs a disability resource centre, most PPSD do not access government services, with a recent study showing that as many as $96 \%$ of people screened as having depression did not have access to care. ${ }^{16}$

A cross-sectional population-based survey was completed in 2015 in Sahaspur block, Dehradun District, in the northern Indian state of Uttarakhand using the Rapid Assessment of Disability (RAD) survey. The RAD survey was developed by the Nossal Institute for Global Health and the Centre for Eye Research Australia at the University of Melbourne, and was validated in Bangladesh and Fiji, and underwent rigorous pretesting and piloting in India to ensure content validity, prior to the actual survey. ${ }^{17}$ Greater detail on the methods used in this study is provided in another paper which examined the prevalence of all types of disability and its associations with health determinants and access and barriers to community services. $^{15}$

\section{Sampling}

The main study was conducted on a sample of 2441 individuals aged 15 years and over from Sahaspur block in Dehradun District. This study used a two-stage cluster random sampling where 50 clusters from 114 villages in Sahaspur block using probability proportion to size sampling, an approach that is useful when the units are of unequal sizes, and ensures the likelihood of a unit being selected is proportionate to the size of the represented population. The second stage involved dividing each selected cluster into five distinct segments from which 10 people aged 18 years and above were selected from each segment to reach a total of 50 participants. Finally, for each person identified to be at risk of disability, an age $( \pm 2$ years) and gender matched control was recruited from an adjacent household to allow a comparison between persons with disabilities (cases) and persons without disability (controls) to understand the barriers of service utilisation and participation.

\section{Data collection and the survey tool}

Eleven data collectors, three of whom had a disability were identified: eight females and three males aged between 19 and 53 years, and given a 4-day training in data collection. The RAD provides the ability to measure disability in a population and understand the barriers to participation across a range of life domains. ${ }^{17}$ The RAD included an interviewer-administered household questionnaire conducted with the household head, and an individual questionnaire. The household questionnaire assessed the household demographics, characteristics and assets.

The individual questionnaire had four sections. Demographic information including age, gender, ethnicity, 
religion, marital status, education level and occupation as section 1 . The second section was self-assessment of functioning designed to capture functional limitations on activities related to vision, hearing, communication, mobility, gross and fine motor skills, cognition, appearance and psychological distress. All study participants $(\mathrm{n}=2441)$ filled sections 1 and 2 of the survey. This study reports on the psychological distress component, which is a modified version of the Kessler-6 (K-6) scale which is a tool validated to screen for both severe and common mental illness, although scoring of K-6 does not recommend a single-parameter cut-off score. ${ }^{18} 19$ The response categories for the modified K-6 used in RAD were 'none', 'some of the time', 'most of the time' and 'all of the time'. As this study was focusing on subjective experiences of limited functioning, participants were considered to have a disability if they had difficulties 'most of the time' or 'all of the time' in at least two domains in the items on Kessler's scale. Section 3 of the RAD comprised 16 questions related to general health, relationships, respect and taking of one's self and assessed the individual's perception of well-being. Questions were reported on a four-point Likert scale ranging from 'never' to 'all of the time'. Section 4 assessed the level of access to different services and participation in the community under domains of employment, health services, community consultations, disabled persons' organisations, social activities, sanitation, safe drinking water and religion. If a participant reported more than one barrier, they were asked to report the most limiting barrier. In this paper, only the most limiting barriers were reported. From the total sample of participants selected for the study, only those identified to have disability and their age matched controls filled sections 3 and 4 ( $n=306$ people) were interviewed for sections 3 and 4 (which address well-being and adult access to community services), and of these, 117 had psychosocial disability and 189 (age and sex matched controls) did not have psychosocial disability.

\section{Statistical analysis}

Statistical analysis used Stata V.14.0. ${ }^{20}$ ORs, both crude and adjusted were calculated using logistic regression to assess the association between psychosocial disability, marital status, age, gender, socioeconomic status, employment and schooling. $\mathrm{X}^{2}$ and Fisher's exact tests were performed.

Any form of school attendance was classified as 'schooled' and the five age categories were used (18-24, 25-34, 35-44, 45-54 and $\geq 55$ years). Employment categories used were employed, not employed and home maker. The reference group characteristics were as follows: male, 18-24 years, any schooling, not married, employed and of high socioeconomic status. To calculate the asset index, principal component analysis was used (rescaled to $0-1$ ) as a proxy for socioeconomic status using categorisations of poor (between 0 and 0.4 ), middle class (between 0.4 and 0.8 ) and rich (between 0.8 and 1). Persons with psychosocial disabilities (cases) and persons without psychosocial disability (controls) were matched for age and sex to understand barriers of service utilisation and participation and compared.

Written informed consent was obtained in ways appropriate for specific disabilities and people who were not literate gave witnessed verbal consent. A plain language statement was provided to each participant.

\section{RESULTS}

Out of 2500 people invited to undertake the survey, 2441 $(97.6 \%)$ surveys were completed. The mean age of the participants was $40.4 \pm 15.2$ years and $51.6 \% \quad(\mathrm{n}=1260)$ were male. Sociodemographic profile of the participants is presented in table 1 .

The prevalence of psychosocial disability according to the study definition was $4.8 \%$, with the prevalence of other types of disability self-reported at $<2 \%$. Of note, the prevalence of psychological distress, with no functional impairment, was only $1.2 \%$ meaning $75 \%$ of participants with psychosocial disability also reported comorbid functional impairments such as difficulties with mobility or eye sight. Table 2 represents a model for the prevalence of psychosocial disability, adjusting for age, gender, marital status, occupation and education.

Table 2 demonstrates that the odds of having psychosocial disability were significantly higher in those with no schooling (2.3 times higher than those with schooling), unemployed people (2.9 times higher than those employed) and people in both the middle and poorer levels of socioeconomic status (3.9 and 4.6 times high respectively than those of rich socioeconomic status). Table 3 explores unmet need among people with and without psychosocial disability.

In table 3, across different access domains the unmet need was significantly higher in every domain for people with psychosocial disability; however, when we removed the group who described that they did not want to participate, the difference between met and unmet need was not significant for Disabled Persons Organisations (DPO). More than a quarter of surveyed people with psychosocial disability described unmet need in relation to work (38\%), health services (28\%) and community consultation $(30 \%)$. However, the unmet need was lower in some other domains as either the participants were not familiar with the service (eg, nearly $80 \%$ of respondents did not know what a DPO was) or did not want to participate. Barriers faced in the different domains of daily life described above were assessed and are summarised in table 4.

People with psychosocial disability encountered greater barriers in every domain compared with matched controls, and table 4 shows that barriers related to lack of information, difficulty getting to services, physical inaccessibility of services, unavailability of services, lack of reasonable accommodation, lack of accompanying assistance accessing services and perceived negative attitudes were significantly higher for PPSD. Table 5 describes 
Table 1 Profile of sociodemographic characteristics of survey participants

\begin{tabular}{|c|c|c|c|}
\hline Categories & Total sample, n (\%) & $\begin{array}{l}\text { People without psychosocial } \\
\text { disability, } n(\%)\end{array}$ & $\begin{array}{l}\text { People with psychosocia } \\
\text { disability, } \mathbf{n}(\%)\end{array}$ \\
\hline Total & $2441(100)$ & $2326(95.2)$ & $117(4.8)$ \\
\hline \multicolumn{4}{|l|}{ Age } \\
\hline $18-24$ years & $410(16.8)$ & $397(17.1)$ & $13(11.0)$ \\
\hline 25-34 years & $544(22.3)$ & $522(22.5)$ & $22(18.6)$ \\
\hline $35-44$ years & $586(24.0)$ & $565(24.3)$ & $21(17.8)$ \\
\hline $45-54$ years & $396(16.2)$ & $381(16.4)$ & $15(12.7)$ \\
\hline$\geq 55$ years & $505(20.7)$ & $458(19.7)$ & $46(39.8)$ \\
\hline \multicolumn{4}{|l|}{ Gender } \\
\hline Male & $1260(51.6)$ & $1196(51.5)$ & $64(54.2)$ \\
\hline Female & $1181(48.4)$ & $1127(48.5)$ & $53(45.8)$ \\
\hline \multicolumn{4}{|l|}{ Schooling } \\
\hline Yes & $1888(77.4)$ & $1828(78.7)$ & $60(50.9)$ \\
\hline No & $553(22.7)$ & $495(21.3)$ & $57(49.2)$ \\
\hline \multicolumn{4}{|l|}{ Socioeconomic status } \\
\hline Poor & 998 (40.9) & $933(40.2)$ & $65(55.1)$ \\
\hline Middle & $983(40.3)$ & $939(40.4)$ & $43(37.3)$ \\
\hline Rich & $460(18.8)$ & $451(19.4)$ & $9(7.6)$ \\
\hline \multicolumn{4}{|l|}{ Marital status } \\
\hline Single & $409(16.8)$ & $389(16.8)$ & $20(17.0)$ \\
\hline Married & $1866(76.4)$ & $1789(77.0)$ & $76(65.3)$ \\
\hline Separated/divorced/widowed & $166(6.8)$ & $145(6.2)$ & $21(17.8)$ \\
\hline \multicolumn{4}{|l|}{ Occupation } \\
\hline Employed & $1222(52.2)$ & $1175(52.9)$ & 47 (40.2) \\
\hline Homemaker & $834(35.7)$ & 796 (35.8) & 38 (32.5) \\
\hline None & $283(12.1)$ & 251 (11.3) & $32(27.4)$ \\
\hline
\end{tabular}

the types of barriers encountered under selected access domains. We present only the domains which demonstrated a consistent difference for people with and without psychosocial disability.

Lack of information about services as a barrier to access was significantly higher for people with psychosocial disability compared with matched controls in the domains of health services, rehabilitation services, safe drinking water, government social services and DPOs, that is in half of the domains described. 'Negative attitudes towards you' was identified as a significant barrier to services for PPSD compared with controls in 6 of the 10 services described above. There was also a significant difference in negative attitudes perceived by people with psychosocial disability compared with controls in over half of the domains, that is, in domains of workplace, health, community consultations, rehabilitation services, safe drinking water and government social welfare services. Surprisingly perhaps, physical accessibility was also a barrier that was significantly greater for people with psychosocial disability compared with controls (described in 8 of 10 domains).

\section{DISCUSSION}

This cross-sectional survey in Sahaspur Block of Dehradun district revealed a prevalence of psychosocial disability of $4.8 \%$, considerably higher than $0.06 \%$ prevalence rate for psychosocial disability described in the 2011 census in Uttarakhand. ${ }^{21}$ The broad definition of PSD used in this survey as well as the use of non-stigmatising language is likely to have led to a higher number of people identified and may explain part of this difference in prevalence. ${ }^{15}$ The prevalence identified in this study aligns with the prevalence of mental illness in India ranging from 3.4\% to $8.9 \%$ described in meta-analytic studies, using a range of tools and definitions ${ }^{22} 23$ and also aligns fairly closely with a recent cross-sectional population survey conducted in the district of Dehradun conducted by the same lead author, that described the prevalence of depression as $6.0 \%$, using a depression screening tool. ${ }^{16}$

This study finds that risks of psychosocial disability are two to four times higher among people who have low education, unemployment and middle or low socioeconomic status. Given that three-quarters of those who identified themselves as having psychosocial disability also 
Table 2 Association between sociodemographic factors and psychosocial disability

Prevalence of psychosocial

disability using Kessler

screening tool (\%); sample Unadjusted OR $(95 \% \mathrm{Cl})$

Categories $n=2411$

$n=117$

Adjusted OR $(95 \% \mathrm{Cl}) \mathrm{n}=117$

Age

18-24 years $\quad 3.17(1.7-5.36)$

25-34 years $\quad 4.04(2.55-6.06)$

35-44 years $\quad 3.58(2.22-5.43)$

45-54 years $\quad 3.79(2.14-6.17)$

$9.11(6.75-11.96)$

$-$

$\geq 55$ years

$4.49(3.38-5.82)$

Female $\quad 4.49(3.38-5.82)$

Male $\quad 5.07$ (3.93-5.44)

$1.12(0.77$ to 1.62$)$

$1.27(0.72$ to 2.21$)$

Schooling

Yes $\quad 3.18(2.43-4.07)$

No $\quad 10.31(7.90-13.15)$

3.6 (2.44 to 5.21$)$

$2.3(1.25 \text { to } 3.85)^{\star}$

Marital status

Married $\quad 4.89$ (3.01-7.45)

Single $\quad 4.07$ (3.22-5.07)

Separate/widowed/divorced 12.65 (8.0-18.68)

$0.81(0.51$ to 1.39$)$

$0.43(0.20 \text { to } 0.95)^{\star}$

$2.82(1.47$ to 5.39$) \quad 3.25(0.56$ to 8.96$)$

Occupation

Employed $\quad 3.84(2.89-5.08)$

Homemaker $\quad 4.43(3.14-6.06)$

Unemployed $\quad 11.31$ (7.86-15.58)

$1.19(0.77$ to 1.85$)$

1.07 (0.58 to 2.0$)$

Socioeconomic status

Rich 1.96 (0.9-3.68)

Middle $\quad 4.37(3.18-5.85)$

$6.41(5.06-8.22)$

2.35 (1.13 to 4.86$)$

$3.90(1.57$ to 9.67$)$ *

Poor

3.49 (1.72 to 7.1$)$

$4.63(1.88 \text { to } 11.43)^{\star}$

${ }^{*}$ Denotes a statistically significant association.

described a comorbid functional impairment, it seems likely that functional impairment itself may increase mental distress. This significant contribution of social determinants of health was also found in the cross-sectional study of depression described above where the risk of depression was two to four times higher among people with limited schooling, poor housing, indebtedness and membership of oppressed castes. ${ }^{16}$ The mechanisms by which social health determinants lead to increased psychosocial disability are likely to be complex with multiple mediating factors. ${ }^{10}$ In this study, we cannot determine the direction of causation; however, a systematic review that assessed links between common mental disorders and poverty similarly found strong relationships between education, housing, socioeconomic status and common mental disorders, a finding supported by other key publications on social determinants of mental health. ${ }^{924}$ Figure 1 shows a possible model for the two-way interaction of poverty and common psychosocial disability in a vicious cycle. We propose that with a social model of disability, disability itself and other functional limitations can be located under the title of 'social causation'.

The high rate of comorbid functional impairment reported in this study suggests a high rate of other forms of disability mixed with psychosocial disability although this cross-sectional study cannot ascertain directionality and causation (it is likely that those with functional impairment are also at higher risk of psychosocial distress). This finding is supported by this study's assessment of barriers to community services where there is a high rate of reporting of physical barriers to services and in particular, identification of the lack of physical access/transport difficulties for people with psycho-social disability. It clearly points to the need for policies and programmes to promote mental health knowledge and skills for all people with disabilities. Additionally, mental health policies and programmes must ensure inclusion of all people with disabilities, and seek to reduce the multiple types of barriers that limit access to care and community participation. 
Table 3 Unmet need in those with psychosocial disability versus those without psychosocial disability (selected domains)

\begin{tabular}{|c|c|c|c|c|c|c|}
\hline Domain & $\begin{array}{l}\text { Need (In the last } 6 \text { months, to } \\
\text { what extent have you been able } \\
\text { to access...?) }\end{array}$ & $\begin{array}{l}\text { People with } \\
\text { PSD ( } n=117)\end{array}$ & $\%$ & $\begin{array}{l}\text { People without } \\
\text { PSD }(n=189)\end{array}$ & $\%$ & $\begin{array}{l}\mathrm{P} \\
\text { Value }\end{array}$ \\
\hline \multirow[t]{2}{*}{ Work } & Met need & 43 & 36.75 & 106 & 56.08 & $<0.001$ \\
\hline & Unmet need & 45 & 38.46 & 27 & 14.29 & \\
\hline \multirow[t]{2}{*}{ Health services } & Met need & 66 & 56.41 & 108 & 57.41 & $<0.001$ \\
\hline & Unmet need & 33 & 28.21 & 25 & 13.23 & \\
\hline \multirow{2}{*}{$\begin{array}{l}\text { Community } \\
\text { consultations }\end{array}$} & Met need & 31 & 25.5 & 95 & 50.26 & $<0.001$ \\
\hline & Unmet need & 36 & 30.77 & 28 & 14.81 & \\
\hline \multirow[t]{2}{*}{ Social activities } & Met need & 52 & 44.44 & 119 & 62.96 & $<0.001$ \\
\hline & Unmet need & 28 & 23.93 & 10 & 5.29 & \\
\hline \multirow[t]{2}{*}{ Sanitation } & Met need & 100 & 85.47 & 187 & 98.94 & $<0.001$ \\
\hline & Unmet need & 17 & 14.53 & 2 & 1.06 & \\
\hline \multirow{2}{*}{$\begin{array}{l}\text { Safe drinking } \\
\text { water }\end{array}$} & Met need & 91 & 77.78 & 176 & 93.12 & $<0.001$ \\
\hline & Unmet need & 26 & 22.22 & 13 & 6.88 & \\
\hline \multirow[t]{2}{*}{ Religion } & Met need & 73 & 62.39 & 139 & 73.54 & 0.001 \\
\hline & Unmet need & 24 & 20.51 & 12 & 6.35 & \\
\hline
\end{tabular}

$\mathrm{NB}$, domains measured but not listed above also addressed rehabilitation services, legal assistance, assistive devices and disaster management.

This study presents one of the first accounts of barriers experienced by people with psychosocial disability for access to services in India. While the total percentage numbers of PPSD who identify barriers to access community services are lower than expected, it is notable that PPSD are significantly more likely to describe barriers in multiple domains of life, when compared with matched controls. While the UNCRPD makes it clear that disability is influenced by both medical limitations and social prejudice, the ways that this plays out for people who suffer from psychosocial disability to limit their community participation are rarely assessed. The three key barriers to participation most frequently identified by participants with psychosocial disability in this study are related to attitudes (negative attitudes towards me), practices (lack of accommodation to support access to services) and structures (eg, making it difficult to get to services), which are similar to findings in a study examining participation of people with psychosocial disability in mental health policy development in South Africa. ${ }^{2}$ Our study shows that people with psychosocial disability describe stigma (negative attitudes) as a significant barrier in nearly half of the domains of services described here. A number of papers have described experiences of stigma of people with psychosocial disability in India and in particular how this can negatively impact access to mental health services $;{ }^{25-27}$ however, this study is likely the first paper to demonstrate how perceived negative attitude interact with domains of community services and participation. Reasons why negative attitudes were not identified as

Table 4 Summary of barriers experienced to access domains of community services

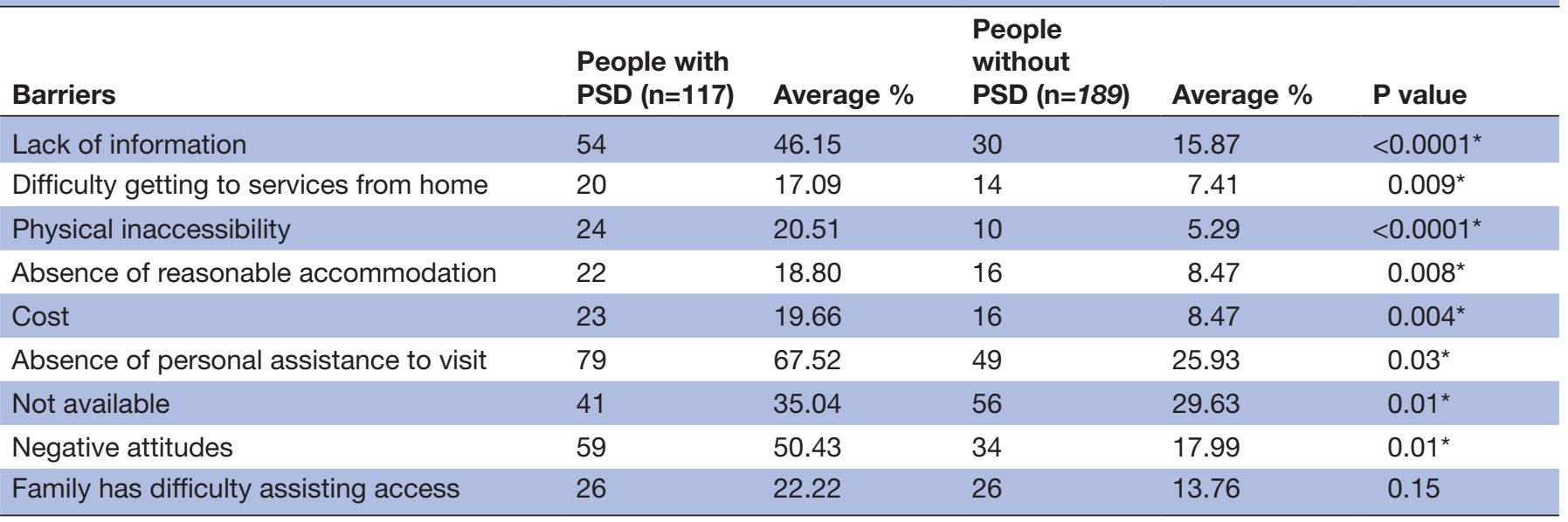

*Indicates findings that are statiscally significant with a probabillity of less than one in 20 that they occured due to chance. 
Table 5 Barriers faced by people with psychosocial disability versus those without (selected access domains)

\begin{tabular}{|c|c|c|c|c|c|}
\hline Barriers & \multicolumn{2}{|c|}{$\begin{array}{l}\text { People with } \\
\text { PSD }\end{array}$} & \multicolumn{2}{|c|}{$\begin{array}{l}\text { People } \\
\text { without PSD }\end{array}$} & $P$ value \\
\hline \multicolumn{6}{|l|}{ Place of work } \\
\hline Lack of information about work & 12 & 10.26 & 10 & 5.29 & 0.10 \\
\hline Negative attitudes towards me at work & 11 & 9.4 & 4 & 2.1 & $<0.001^{*}$ \\
\hline Difficulty getting to work from home & 17 & 14.5 & 11 & 5.8 & $0.01^{*}$ \\
\hline \multicolumn{6}{|l|}{ Health } \\
\hline Lack of information about health services & 18 & 15.4 & 12 & 6.4 & $0.01^{*}$ \\
\hline Negative attitudes towards me & 8 & 6.8 & 4 & 2.1 & $0.04^{*}$ \\
\hline Difficulty getting to health services & 13 & 11.1 & 8 & 4.2 & $0.02^{*}$ \\
\hline \multicolumn{6}{|l|}{ Community consultations } \\
\hline Lack of information about community consultations & 14 & 12.0 & 18 & 9.5 & 0.50 \\
\hline Negative attitudes towards me & 12 & 10.3 & 2 & 1.1 & $<0.001^{*}$ \\
\hline Difficulty getting to community meetings from home & 16 & 13.7 & 7 & 3.7 & $<0.001^{*}$ \\
\hline \multicolumn{6}{|l|}{ Rehabilitation services } \\
\hline Lack of information about rehabilitation services & 19 & 16.2 & 12 & 6.4 & $0.01^{*}$ \\
\hline Negative attitudes towards you from rehabilitation services & 4 & 3.4 & 0 & 0 & $0.01^{*}$ \\
\hline Difficulty getting to rehabilitation services from home & 9 & 7.7 & 8 & 4.2 & 0.20 \\
\hline \multicolumn{6}{|l|}{ Safe drinking water } \\
\hline Lack of information about accessible safe water & 5 & 4.3 & 1 & 0.5 & $0.02^{*}$ \\
\hline Negative attitudes towards me & 6 & 5.1 & 1 & 0.5 & $0.01^{*}$ \\
\hline $\begin{array}{l}\text { Difficulty getting to safe water supplies (eg, pumps, wells) } \\
\text { from home }\end{array}$ & 8 & 6.8 & 3 & 1.6 & $0.02^{*}$ \\
\hline \multicolumn{6}{|l|}{ Social activities } \\
\hline Lack of information about social activities & 5 & 4.3 & 3 & 1.6 & 0.15 \\
\hline Negative attitudes towards me & 5 & 4.3 & 2 & 1.1 & 0.07 \\
\hline Difficulty getting to social venues from home & 13 & 11.1 & 1 & 0.5 & $<0.001^{*}$ \\
\hline \multicolumn{6}{|l|}{ Religion } \\
\hline Lack of information about religious activities & 5 & 4.3 & 3 & 1.6 & 0.15 \\
\hline Negative attitudes towards me & 5 & 4.3 & 2 & 1.1 & 0.07 \\
\hline Difficulty getting to religious venues from home & 11 & 9.4 & 3 & 1.6 & $<0.001^{*}$ \\
\hline \multicolumn{6}{|l|}{ Government social welfare services } \\
\hline Lack of information about government social services & 12 & 10.3 & 6 & 3.2 & $0.01^{\star \star}$ \\
\hline Negative attitudes towards me & 9 & 7.7 & 0 & 0.00 & $<0.001^{*}$ \\
\hline Difficulty getting to social welfare services & 5 & 4.3 & 1 & 0.5 & $0.02^{*}$ \\
\hline \multicolumn{6}{|l|}{ Disabled Persons Organisations (DPO) } \\
\hline Lack of information about DPO services $\dagger$ & 11 & 9.4 & 3 & 1.6 & $<0.001^{*}$ \\
\hline Negative attitudes towards me & 1 & 0.9 & 1 & 0.5 & 0.73 \\
\hline Difficulty getting to DPO venue from home & 5 & 4.3 & 3 & 1.6 & 0.152 \\
\hline \multicolumn{6}{|l|}{ Education } \\
\hline Lack of information about education or training & 14 & 12.0 & 11 & 5.82 & 0.06 \\
\hline Negative attitudes towards you & 4 & 3.4 & 1 & 0.53 & 0.05 \\
\hline Difficulty getting to education or training facilities & 7 & 6.0 & 2 & 1.06 & $0.01^{*}$ \\
\hline
\end{tabular}

†Other aspects of the DPO domain had too few numbers for useful analysis.

*Indicates findings that are statiscally significant with a probabillity of less than one in 20 that they occured due to chance. 


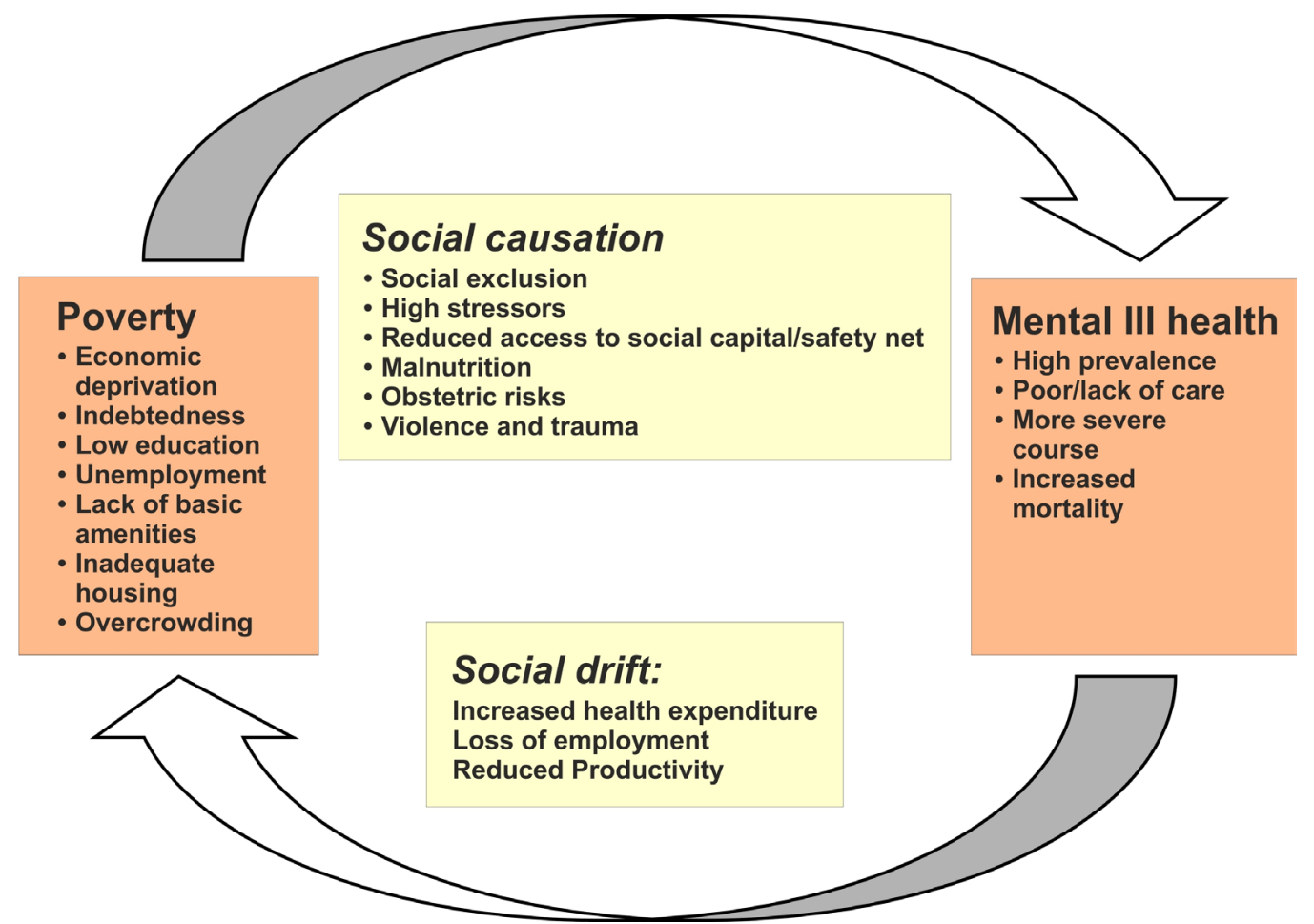

Figure 1 Diagram developed by Crick et al, proposing a two-way interaction between poverty and mental ill health. ${ }^{10}$

limiting access to some community services is not clear and this is an area that requires further research. The impact of multiple marginalities such as membership of an excluded social group or having female gender and low education status adding to the disadvantage of disability has been identified as a basis for additional exclusion of those with PSD. ${ }^{28} 29$

In the multiple domains assessed in this study, lack of information and physical accessibility were also frequently perceived as barriers to participation by people with psychosocial disability. The contribution of co-existing functional impairment is likely to explain the barriers related to physical accessibility and transport. While lack of access to information is high (34\%) in the general community, it is even higher for people with PSD (50\%). Possible reasons why lack of information appears to be a greater barrier for people with psychosocial disability could be that this group has lower literacy and fewer social contacts and networks (so less information comes their way), and that they are less motivated in seeking out information. Perhaps this group has also reduced access to mass media such as television or radio.

There are ample policies and legal structures to promote access and participation for people with disabilities in India including those with PSD. India was one of the first countries to sign the UNCRPD and recently passed the Mental Health Care Act (2017), both documents of which include components to support participation and access to services. The new Rights of Persons with Disabilities Act (2016) clearly includes people with mental illness, and builds on the Persons with Disabilities Act (1995) to push for a more disabled inclusive and accessible environment. ${ }^{30}$ At the same time, we join with others to observe that access to services and participation for people with PSD remains limited, and implementation and regulation are very weak links in the chain in relation to health services and policies in India. ${ }^{30} 31$

Programmatic implementation at all levels must intentionally seek to include people with psychosocial disability. This demands attention to increasing the accessibility of community-level structures such as transport and dissemination of information related to services and entitlements so that they reach people with psychosocial disability. This will require using mediums that are accessible to those who have low literacy and who have limited social networks such as loudspeaker announcements which are used widely and effectively by campaigning political parties in India. It also requires changes in attitudes at all levels in the community and among service providers. A number of steps can be taken to reduce stigma and increase social inclusion in programmes related to health, education and sanitation which include increasing awareness in the community, educating service providers and increasing direct contact between people with psychosocial disability and others. ${ }^{32}$

A further clear message from this study is that since risk and protective factors for mental health act at several different levels, and include macroeconomic health determinants, responses to them need to be multilayered and multisectoral. Macropolicies that address poverty, education, welfare, transport, housing and employment sectors are required, with a 'health in all policies' approach, ${ }^{9}$ and seems likely to also reduce the disease burden related to psychosocial disability. ${ }^{33}$ 


\section{Methodological considerations}

The Kessler tool is a screening rather than diagnostic tool, and excluded two key risk factors for psychosocial disability: stressful life events and chronic illness. While the K-6 scale has been found to have moderate-to-high discriminating ability when used by lay workers in identifying common mental disorders in India, ${ }^{34}{ }^{35}$ it did not screen for the whole spectrum of psychosocial disability. A limitation of the findings presented in tables 3 and 5 particularly is that the numbers are small reducing the reliability of the findings and meaning that some findings that may well have been significant with a larger sample were not elucidated. The study is limited to adults of over 18 years of age, and so cannot assess the prevalence of psychosocial disability or barriers they face, among children. As the RAD survey tool used self-reported data, there may be a risk of social desirability or recall bias. As a cross-sectional survey, it cannot attribute causality to apparent risk factors. A major strength of this study is that its data are from a randomly selected population covering rural, semi-urban and urban populations in North India which increases the generalisability of the findings, and suggests that they may be applicable to other urban and rural settings in North India. Multivariable analysis ensured that potentially confounding factors were considered.

\section{CONCLUSIONS}

Psychosocial disability in Dehradun district, Uttarakhand, with a prevalence of at least $4.8 \%$ is two or three times more common among people with comorbid functional impairment who are economically deprived, who have had little education and who are unemployed. People with psychosocial disability face significant unmet needs related to community services and perceive negative social attitudes as a significant barrier limiting their participation in multiple domains. Social policy and programmes in India must take active steps to address social determinants of psychosocial disability such as increasing access to education and reduce economic deprivation. Additionally, action is needed at all levels of community programmes and services to increase social inclusion of people with psychosocial disability.

Acknowledgements The authors would like to thank CBM for the funding support, their responsiveness and helpful engagement throughout the duration of the entire RAD project. With CBM's sponsorship, the Public Health Foundation of India and the Nossal Institute for Global health of the University of Melbourne became partners in conducting this research. We acknowledge the support of field research teams under the CHGN Uttarakhand Cluster for their support in data collection. The teams were AKS HOPE, OPEN, Chamba Christian hospital and EHA (Samvedna and Anugrah projects).

Contributors NG, GVSM and MM conceived of the study and the overall design, $\mathrm{HP}$ and KM performed data analysis, and KM wrote the first and subsequent drafts. LS supported data collection and NG and MM supported study design, analysis and overview of the whole paper. All authors provided input into drafts of the paper.

Funding CBM (an international development organisation with a focus on disability) funded this research. As they are not a research council they do not use grant numbers.
Competing interests None declared.

Patient consent Obtained.

Ethics approval The ethics committee at the Indian Institute of Public Health Hyderabad and the ethics committee of the CHGN Uttarakhand Cluster granted ethics approval.

Provenance and peer review Not commissioned; externally peer reviewed.

Data sharing statement There is no additional unpublished data from this study available.

Open Access This is an Open Access article distributed in accordance with the Creative Commons Attribution Non Commercial (CC BY-NC 4.0) license, which permits others to distribute, remix, adapt, build upon this work non-commercially, and license their derivative works on different terms, provided the original work is properly cited and the use is non-commercial. See: http://creativecommons.org/ licenses/by-nc/4.0/

(c) Article author(s) (or their employer(s) unless otherwise stated in the text of the article) 2018. All rights reserved. No commercial use is permitted unless otherwise expressly granted.

\section{REFERENCES}

1. Drew N, Funk M, Tang S, et al. Human rights violations of people with mental and psychosocial disabilities: an unresolved global crisis. Lancet 2011;378:1664-75.

2. Kleintjes S, Lund C, Swartz L. Barriers to the participation of people with psychosocial disability in mental health policy development in South Africa: a qualitative study of perspectives of policy makers, professionals, religious leaders and academics. BMC Int Health Hum Rights 2013;13:17.

3. Braithwaite J, Mont D. Disability and poverty: a survey of world bank poverty assessments and implications. ALTER - European Journal of Disability Research / Revue Européenne de Recherche sur le Handicap 2009;3:219-32.

4. McSherry B. The United Nations convention on the rights of persons with disabilities. J Law Med 2008;16:17-20.

5. Link BG, Phelan JC. Conceptualizing Stigma. Annu Rev Sociol 2001;27:363-85.

6. Popay J, Escorel S, Hernandez M, et al. Understanding and tackling social exclusion - Final Report to the WHO Commission on Social Determinants of Health WHO Social Exclusion Knowledge Network. Geneva: World Health Organisation, 2008.

7. Baumgartner JN, Burns JK. Measuring social inclusion--a key outcome in global mental health. Int J Epidemiol 2014;43:354-64.

8. Collins PY, Patel V, Joestl SS, et al. Grand challenges in global mental health. Nature 2011;475:27-30.

9. Organization WH. Social determinants of mental health. Geneva: World Health Organization, 2014.

10. Lund C, Breen A, Flisher AJ, et al. Poverty and common mental disorders in low and middle income countries: a systematic review. Soc Sci Med 2010;71:517-28.

11. Campbell C, Jovchelovitch S. Health, community and development: towards a social psychology of participation. J Community App/ Soc Psychol 2000;10:255-70.

12. Bandura A. Self efficacy in changing societies. Cambridge: Cambridge University Press, 1996.

13. Baum F, Palmer C. 'Opportunity structures': urban landscape, social capital and health promotion in Australia. Health Promot Int 2002;17:351-61.

14. Mathias K, Kermode M, San Sebastian M, et al. Under the banyan tree--exclusion and inclusion of people with mental disorders in rural North India. BMC Public Health 2015;15:446.

15. Grills N, Singh L, Pant H, et al. Access to Services and Barriers faced by People with Disabilities: a quantitative survey. Disability, CBR \& Inclusive Development 2017;28:23-44.

16. Mathias K, Goicolea I, Kermode M, et al. Cross-sectional study of depression and help-seeking in Uttarakhand, North India. BMJ Open 2015;5:e008992.

17. Marella M, Busija L, Islam FM, et al. Field-testing of the rapid assessment of disability questionnaire. BMC Public Health 2014;14:900.

18. Kessler RC, Barker PR, Colpe LJ, et al. Screening for serious mental illness in the general population. Arch Gen Psychiatry 2003;60:184-9.

19. Kessler RC, Andrews G, Colpe LJ, et al. Short screening scales to monitor population prevalences and trends in non-specific psychological distress. Psychol Med 2002;32:959-76.

20. LP SC. Stata statistical software. College Station: StataCorpLP, 2015. 
21. Government of India. Census 2011. 2011 http://www.census2011.co. in/census (accessed 29 Sep 2014).

22. Ganguli HC. Epidemiological findings on prevalence of mental disorders in India. Indian J Psychiatry 2000;42:14-20.

23. Reddy VM, Chandrashekar C. Prevalence of mental and behavioural disorders in India: a meta-analysis. Indian J Psychiatry 1998;40:149.

24. World Health Organisation. Risks to mental health : an overview of vulnerabilities and risk factors. WHO Secretariat for the development of a comprehensive mental health action plan. Geneva: WHO, 2012.

25. Koschorke M, Padmavati R, Kumar S, et al. Experiences of stigma and discrimination of people with schizophrenia in India. Soc Sci Med 2014;123:149-59.

26. Raguram R, Raghu TM, Vounatsou P, et al. Schizophrenia and the cultural epidemiology of stigma in Bangalore, India. J Nerv Ment Dis 2004;192:734-44.

27. Venkatesh BT, Andrews T, Mayya SS, et al. Perception of stigma toward mental illness in South India. J Family Med Prim Care 2015;4:449-53.

28. Mehrotra N. Disability, gender and caste: marginality, exclusion and opportunities in indian economy. Women's Link 2012;18:5-8.
29. Mehrotra N. Negotiating gender and disability in Rural Haryana. Sociol Bull 2006;55:406-26.

30. Mehrotra N. Disability rights movements in India: Politics and practice. Econ Political Wkly 2011;46:65-72.

31. Addlakha R, Mandal S. Disability law in India: paradigm shift or evolving discourse? Econ Political Wkly 2009;44:41-2.

32. Collins R, Wong E, Cerully J. Interventions to reduce mental health stigma and discrimination - a literature review to guide evaluation of California's mental health prevention and early intervention initiative. Los Angeles: California Mental Health Services Authority, 2012.

33. Lund C, De Silva M, Plagerson S, et al. Poverty and mental disorders: breaking the cycle in low-income and middle-income countries. Lancet 2011;378:1502-14.

34. Chowdhary N, Patel V. Detection of common mental disorder and alcohol use disorders in HIV infected people: A validation study in Goa, India. Asian J Psychiatr 2010;3:130-3.

35. Patel V, Araya R, Chowdhary N, et al. Detecting common mental disorders in primary care in India: a comparison of five screening questionnaires. Psychol Med 2008;38:221-8. 
Correction: Multiple barriers to participation for people with psychosocial disability in Dehradun district, North India: a cross-sectional study

Mathias K, Pant H, Marella M, et al. Multiple barriers to participation for people with psychosocial disability in Dehradun district, North India: a cross-sectional study. BMJ Open 2018;8:e019443. doi: 10.1136/bmjopen-2017-019443

The third author, 'Manju Marella' should be written 'Manjula Marella'.

Open Access This is an Open Access article distributed in accordance with the Creative Commons Attribution Non Commercial (CC BY-NC 4.0) license, which permits others to distribute, remix, adapt, build upon this work non-commercially, and license their derivative works on different terms, provided the original work is properly cited and the use is non-commercial. See: http://creativecommons.org/licenses/by-nc/4.0/

C Article author(s) (or their employer(s) unless otherwise stated in the text of the article) 2018. All rights reserved. No commercial use is permitted unless otherwise expressly granted.

BMJ Open 2018;8:e019443corr1. doi:10.1136/bmjopen-2017-019443corr1

(A) Check for updates 